\title{
El requisito de Agotamiento de Recursos Internos, ¿Principio de Derecho Internacional?
}

The Requirement of Depletion of Internal

Resources, Principle of International Law?

A exigência de esgotamento de recursos internos, principio de direito internacional?

L'exigence d'épuisement des ressources internes, principe du droit international?

消耗内部资源的要求国际法原则?

\section{Matias Manelli ${ }^{1}$ \\ Universidad de Buenos Aires - Argentina}

Revista Derechos en Acción ISSN 2525-1678/ e-ISSN 2525-1686

Año 5/No 17 Primavera 2020 (21 septiembre a 20 diciembre), 193-223

DOl: https://doi.org/10.24215/25251678e457

Recibido: 01/09/2020

Aprobado: 15/09/2020

Resumen: El presente trabajo reconstruye, desde una perspectiva comparada, el alcance del requerimiento de Agotamiento de Recursos Internos (ARI) y las excepciones admitidas en los tribunales internacionales. Para ello, se analizan antecedentes jurisprudenciales de distintos sistemas internacionales y, subsidiariamente, regulaciones generales en los casos en los que no existan en la jurisprudencia que haga referencias

1 Filiación Institucional: Facultad de Derecho - Universidad de Buenos Aires. Correo Electrónico: mmanelli@derecho.uba.ar. Profesor para la Enseñanza Media y Superior en Ciencias Jurídicas (UBA). Auxiliar docente en Facultad de Derecho (UBA). Maestrando en Ciencias Sociales con Orientación en Educación (FLACSO) (ORCID: https://orcid.org/ 0000-0001-9247-1317). 
directas al instituto, ello con el fin de identificar el alcance y, por ende, las limitaciones en torno a la regla de ARI en tanto principio de Derecho Internacional, teniendo en consideración que el desarrollo de las distintas jurisdicciones y, consecuentemente, del Derecho Internacional se da en un escenario de fragmentación. En dicho sentido, en los casos en los que no se da un abordaje de la categoría en cuestión se reconstruirán categorías análogas, subsumiendo el objeto de análisis en las condiciones de admisibilidad en general. La hipótesis que orienta este trabajo afirma que la regla de ARI es flexible a nivel global, en un contexto de fragmentación que si bien condiciona su sistematización no imposibilita la identificación de tendencias comunes. El estudio realizado llevó a concluir que el grado de heterogeneidad de las jurisdicciones impide afirmar que la regla constituya un principio de aplicación general.

Palabras clave: Derecho Internacional - Agotamiento de Recursos Internos - Jurisdicciones Internacionales - Condiciones de Admisibilidad -

Abstract: This paper reconstructs from a comparative perspective the scope of the requirement of exhaustion of local remedies (ELR) and the exceptions allowed in the international courts. For this, jurisprudential antecedents from diferente international systems are analyzed and, subsidiarily, general regulations in cases where there are no jurisprudence that refers to the concept, this in order to identify the scope and, therefore, the limitations around the ELR rule as a principle of international law, taking into consideration that the development of the different jurisdictions and, consequently, of International Law occurs in a scenario of fragmentation. In this sense, in the cases in which an approach to the category in question is not given, analogous categories will be reconstructed, subsuming the object of analysis in the conditions of admissibility in general. The hypothesis that guides this work affirms that the ELR rule is flexible at a global level, in a context of fragmentation that, although it conditions its systematization, does not make it impossible to identify common trends. The study carried out led to the conclusion that the degree of heterogeneity of the jurisdictions makes it impossible to affirm that the rule constitutes a principle of general application.

Keywords: International Law - Exhaustion of Local Remedies - International Jurisdictions - admissibility conditions. 
Resumo: 0 presente trabalho reconstrói, numa perspetiva comparativa, 0 âmbito do requisito de Esgotamento de Recursos Internos (ERI) e as exceções admitidas nos tribunais internacionais. Para tanto, são analisados antecedentes jurisprudenciais de diferentes sistemas internacionais e, alternativamente, regulamentações gerais nos casos em que não haja na jurisprudência que faça referências diretas ao instituto, a fim de identificar o alcance e, portanto, as limitações. em torno da regra do ARI como princípio do Direito Internacional, levando em consideração que o desenvolvimento das diferentes jurisdições e, conseqüentemente, do Direito Internacional ocorre em um cenário de fragmentação. Nesse sentido, nos casos em que a categoria em questão não seja abordada, serão reconstruídas categorias análogas, subsumindo o objeto de análise nas condições de admissibilidade em geral. A hipótese que norteia este trabalho afirma que a regra ARI é flexível a nível global, num contexto de fragmentação que, embora condicione a sua sistematização, não impossibilita a identificação de tendências comuns. 0 estudo realizado permitiu concluir que o grau de heterogeneidade das jurisdições não permite afirmar que a norma constitui um princípio de aplicação geral.

Palavras-chave: Direito Internacional, Esgotamento de Recursos Domésticos, Jurisdições Internacionais, Condições de Admissibilidade

Résumé: Le présent travail reconstruit, dans une perspective comparative, la portée de l'exigence d'épuisement des ressources internes (ERI) et les exceptions admises dans les tribunaux internationaux. Pour cela, des antécédents jurisprudentiels de différents systèmes internationaux sont analysés et, à titre subsidiaire, des réglementations générales dans les cas où il n'y a pas dans la jurisprudence qui fait des références directes à l'institut, afin d'identifier la portée et, par conséquent, les limites. autour de la règle $A R I$ en tant que principe du droit international, en tenant compte du fait que le développement des différentes juridictions et, par conséquent, du droit international se produit dans un scénario de fragmentation. En ce sens, dans les cas où la catégorie en question n'est pas abordée, des catégories analogues seront reconstruites, subsumant l'objet d'analyse dans les conditions de recevabilité en général. L'hypothèse qui guide ce travail affirme que la règle $A R I$ est flexible au niveau global, dans un contexte de fragmentation qui, bien qu'elle conditionne sa systématisation, ne rend pas impossible l'identification 
de tendances communes. L'étude menée a conduit à la conclusion que le degré d'hétérogénéité des juridictions ne permet pas d'affirmer que la règle constitue un principe d'application générale.

Mot-clés: Droit international, Épuisement des ressources nationales, Juridictions internationales, Conditions de recevabilité

摘要: 从比较的角度来看, 本工作重构了内部资源用尽要求的范围 以及国际法院承认的例外情况. 为此, 对不同国际制度的判例先例 进行分析, 或者, 在判例中没有直接引用该机构的判例的情况下, 通 则采用一般规则, 以便确定范围和局限. 考虑到ARI规则作为国际法 的原则, 并考虑到不同司法管辖区以及因此国际法的发展是在零散 的情况下发生的. 从这个意义上说，如果没有给出所讨论类别的方 法, 则将重构类似类别, 并将分析对象纳入一般可采性条件下. 指导 这项工作的假说肯定了ARI规则在全球范围内是灵活的，在零散的 情况下, 尽管这限制了它的系统化, 但并不能确定共同的趋势. 这项 研究得出的结论是, 司法管辖区的异质程度使其无法肯定该规则构 成了普遍适用的原则。

关键字: 国际法, 耗尽国内资源, 国际管辖区, 受理条件

\section{Introducción}

Si bien existe un desarrollo teórico profundo en cuanto a los alcances, límites y excepciones de la regla de agotamiento de recursos internos (en adelante, "ARI") como principio general en el Sistema Interamericano ${ }^{2}$, así como también se da cuenta en la literatura especializada la primacía de dicha regla en tanto principio general, no se puede establecer con exactitud el grado de rigidez; el alcance de dicha regla general a nivel global. En este sentido, resulta propicio indagar en la jurisprudencia de las jurisdicciones internacionales cuál es el alcance del requisito del ARI, en el marco de la interpretación que los tribunales realizan

\footnotetext{
2 Ver (entre otros): FAUNDEZ LEDESMA, H. (2004). "El sistema interamericano de protección de los derechos humanos: aspectos institucionales y procesales". San José. Costa Rica: Instituto Interamericano de Derechos Humanos; PINTO, M. (1993). "La denuncia ante la Comisión Interamericana de Derechos Humanos". Buenos Aires. Argentina: Editores del Puerto S.R.L.
} 
de las controversias en trato. La cuestión está exhaustivamente desarrollada en la literatura especializada en torno al Sistema Interamericano, pero no existe una lectura integral que permita delimitar un estado de la cuestión relativo al alcance de dicho principio de derecho internacional consuetudinario. Siendo que se trata de un principio general del derecho internacional, resulta significativa la indagación del estado de la cuestión, de modo que se visibilicen los estándares internacionales en la materia y así poder determinar los alcances y límites del principio.

En este marco, la hipótesis del presente trabajo afirma que el principio según el cual se exige, como condición para el acceso a la jurisdicción internacional, el agotamiento de los recursos internos del Estado en cuestión es flexible a nivel global y en ningún caso restrictivo, primando el acceso a las jurisdicciones internacionales por sobre la ponderación de las jurisdicciones locales en virtud de un criterio amplio de admisibilidad, todo ello en un contexto de fragmentación que si bien condiciona su sistematización no imposibilita la identificación de tendencias comunes.

Se entenderá que la jurisprudencia adopta un criterio flexible cuando el tribunal en cuestión admite la controversia con independencia del incumplimiento, en rigor, del requisito de ARI. Se considerarán casos de cumplimiento rígido o restrictivo aquellos donde la aplicación de la regla general se aplique sin considerar supuestos materiales que puedan incidir en el cumplimiento de la regla. En los casos en los que la regla no exista per sé, se reconstruirán las condiciones de admisibilidad que puedan asimilarse al ARI, considerando no obstante el caso como un supuesto que cumple con el principio general.

\section{La identificación de estándares comunes en un escenario de fragmentación del Derecho Internacional}

La indagación que este trabajo se propone se inscribe en una dimensión problemática para la investigación jurídica en Derecho Internacional como lo es el carácter fragmentario de sus 
instituciones. En primer término, el escenario internacional da cuenta del grado de internacionalización del derecho: no hay ámbito social que no cuente con regulación jurídica internacional. En tal sentido, desde comienzos del Siglo XX han proliferado distintos sistemas y regímenes normativos, a escala global, regional o particular (Brotons, 1997, pág. 81). Todos estos sistemas cuentan con distintos grados de institucionalización y competencia, y exhiben el carácter coordinatorio del Derecho Internacional (Brotons, 1997, pág. 82), carente de instituciones centralizadas que aseguren la homogeneidad de cada una de las unidades que hacen al ámbito jurídico internacional. En este marco, la identificación de reglas y/o principios comunes resulta compleja, dado el grado de heterogeneidad a priori, pero resulta prioritaria a fin de poder establecer un estado de situación actual en torno a este fenómeno, como es el caso de la regla de ARI.

\section{El requisito Agotamiento de Recursos Internos (ARI)}

El ARI es un principio según el cual se deben agotar los remedios legales locales, en el marco de la controversia a nivel local, como condición para poder establecer una acción internacional. Su fundamento está dado por la soberanía y la jurisdicción del Estado competente para conocer de la cuestión por conducto de sus propios órganos judiciales, ya que se considera necesario que el Estado donde se dio la infracción tenga la posibilidad de rectificar la situación por sus propios medios y en el marco de su propio ordenamiento jurídico (González Napolitano, 2015, pp. 928-929).

El ARI es una de las condiciones del ejercicio de la protección diplomática, según ha sido reconocido en la jurisprudencia internacional en tanto principio bien establecido del Derecho Internacional Consuetudinario. Esto quiere decir que, para someter una cuestión que atañe a un sujeto de derecho internacional a la jurisdicción de un tribunal internacional, se exige el agotamiento de la vía jurisdiccional interna. 
Este instituto surgió en el ámbito de la protección diplomática de los extranjeros, que permite al Estado hacer suyas las reclamaciones de sus nacionales en contra de terceros Estados, convirtiendo a los primeros en un legítimo objeto de protección del Estado, aunque no en sujeto del Derecho Internacional. Para que el Estado intervenga, el individuo debe haber agotado los recursos de la jurisdicción interna.

El ARI tiene correlato con la obligación de garantizar el acceso de justicia a los extranjeros. Los estados deben garantizar el derecho a la jurisdicción a través de su administración de justicia, ya que, de lo contrario, los mismos incurrirían en responsabilidad internacional. Los antecedentes jurisprudenciales en general y los estatutos de los tribunales internacionales en particular tienden a contemplar excepciones a este requerimiento, a fin de comprender los casos en los que el ARI resulta de imposible realización por distintos factores que pueden incidir en él. Estas constituyen las excepciones al principio general. El sujeto damnificado puede ser un Estado, un individuo o ambos simultáneamente.

Con relación a las excepciones al principio general según el cual se requiere el ARI, en el caso del Sistema Interamericano de Derechos Humanos, existe un profundo desarrollo jurisprudencial acerca del mismo. Dicho desarrollo jurisprudencial permite reconstruir los alcances, límites y, por tanto, excepciones al principio. En este sentido, si el Estado en cuestión no cuenta con los mecanismos legales e institucionales, o bien haya obstaculizado el acceso al damnificado, o bien no están disponibles por cualquier cuestión de hecho, entonces el requerimiento de admisibilidad establecido por el principio general no corresponde (González Napolitano, 2015, Pág. 929).

Con el reconocimiento de la subjetividad internacional de los individuos, se contempla la actuación por iniciativa propia, con independencia del Estado. En cualquiera de los supuestos, sigue estando sujeta al agotamiento de los recursos de la jurisdicción local. En este sentido, se trataría de la contrapartida del derecho de petición individual (Faúndez Ledesma, 2007, pp. 16-17). 
La regla del agotamiento es una regla general que permite desarrollar los términos en que ella será aplicada, e indicar las posibles excepciones a la misma. El ARI puede entenderse, o bien como una regla procesal (Faúndez Ledesma, 2007, pág. 19) - en tanto el incumplimiento de la obligación internacional es independiente del agotamiento - o bien sustantiva, cuando el hecho ilícito objeto de la controversia es el propio agotamiento. Parte de la jurisprudencia internacional - se puede hacer referencia, particularmente a la de la Corte IDH - plantea que la misma constituye una defensa por parte del Estado, que debe ser invocada expresamente.

Asimismo, la regla de ARI es caracterizada como una regla flexible, no absoluta. Si bien se parte de la primacía de los tribunales nacionales en la administración de justicia -una violación de un derecho no puede llevarse directamente a jurisdicción internacional - se contempla la posibilidad de omitir este requerimiento de admisibilidad y acceder a los tribunales internacionales (Del Castillo, 2012, pp. 145-146).

Por ende, se puede sostener que hay una noción general en torno al principio general y existen excepciones plasmadas normativamente, así como en el desarrollo jurisprudencial de los distintos tribunales internacionales, no habiendo una sistematización doctrinaria al respecto a escala global.

\section{El agotamiento de recursos internos en las jurisdicciones internacionales}

\section{IV.1. Corte Internacional de Justicia (CIJ)}

En primer término, se puede mencionar la decisión respecto del caso "Mavrommatis" ${ }^{3}$ del antecedente institucional de la CIJ, la Corte Permanente de Justicia Internacional, en el

\footnotetext{
3 Corte Permanente de Justicia Internacional. "Las concesiones palestinas de Mavrommatis" (Grecia c. Reino Unido de Gran Bretaña) Excepciones Preliminares, Sentencia del 30 de agosto de 1924, Serie A, No. 2, I.P.C.J.
} 
que el Estado Griego accionó contra Gran Bretaña, quien había obtenido mandato sobre el territorio de Palestina, debido a la negativa por parte de este último de reconocer derechos de concesión sobre obra pública otorgados por el extinto Imperio Otomano a Mavrommatis, de nacionalidad griega. En este caso, el tribunal estableció que es potestad de todo Estado proteger a sus nacionales ante los daños que puedan ocasionar otros estados, en tanto principio de derecho internacional. En este sentido, en el marco del conflicto suscitado entre los estados, Mavrommatis no podía cumplir con el requisito de ARI ya que no pudo hacerlo en la jurisdicción local del Mandato de Palestina, asumiendo el reclamo el Estado griego por su nacional, planteándose entonces como excepción al principio de ARI que la persona esté impedida de ejercer los recursos internos (González Napolitano, 2015, pág. 929).

Por su parte, ya en el marco de la CIJ, el precedente Interhandel (Suiza c. Estados Unidos de América) ${ }^{4}$ estableció que el Estado suizo no podía asumir la reclamación internacional en nombre de la empresa Interhandel, que operaba en los Estados Unidos, dado que dicha firma no había cumplido con agotar previamente las vías internas. En este sentido, Estados Unidos, con posterioridad a la presentación efectuada por Suiza, había permitido a la empresa Interhandel reanudar el proceso. Asimismo, el tribunal reconoció que el sistema de justicia norteamericano contaba con remedios locales adecuados, por lo que correspondía aplicar el principio que obligaba a agotar los recursos internos. la misma resolución judicial. Por su parte, el caso Electrónica Sicula ${ }^{5}$, consagra el principio y su estatus de norma consuetudinaria. En dicho precedente, el tribunal sostiene que el Estado italiano no había demostrado que existían recursos sin utilizar y agotar por parte de las empresas

4 Corte Internacional de Justicia. Caso Interhandel (Suiza c. Estados Unidos)", (Excepciones preliminares), Sentencia del 21 de marzo de 1959, I.C.J. Reports, 1959.

5 Corte Internacional de Justicia. "Caso Sicula S.P.A. (Sicula S.P.A. c. Italia)". Fallo del 20 de julio de 1989. 
estadounidenses, por lo que la pretensión de excepción a la admisibilidad del reclamo internacional por no haber agotado los recursos internos fue rechazada, en tanto el reclamo preliminar versaba sobre la esencia de la reclamación presentada ante el tribunal. Entonces, el precedente deja un margen de interpretación flexible del principio, en tanto se admite la controversia en tanto se haya realizado el reclamo en la jurisdicción local y perseverado en torno a la esencia de la cuestión, con independencia de la existencia de otras instancias, no esclarecidas por el Estado italiano.

En el caso de la CIJ, entonces, a partir de los casos abordados se puede afirmar que se consagra el estatus de norma consuetudinaria del requerimiento de ARI para el acceso a la jurisdicción internacional, pero a la vez ha establecido excepciones a la regla general, dando cuenta de su carácter flexible al respecto, incluso en casos donde la ha consagrado.

\section{IV.2 Centro Internacional de Arreglo de Diferencias Relativas a Inversiones (CIADI)}

El CIADI, en tanto órgano de solución pacífica de controversias, tiene antecedentes pasibles de ser leídos desde la regla de ARI que merecen ciertas consideraciones. los tribunales arbitrales constituidos en el marco del CIADI han emitido laudos arbitrales que permiten reconstruir determinados estándares en la materia.

En primer término, corresponde mencionar que el Convenio CIADI establece en su artículo 26 que el procedimiento de arbitraje en el marco del órgano excluye cualquier otro recurso, que el agotamiento de vías administrativas y judiciales pueden ser exigidos en el marco de los tratados bilaterales pero dicha condición no es obligatoria. Siendo que el requerimiento de ARI se subsume en los dispuesto en los Tratados Bilaterales de Inversión, es importante considerar al respecto que la gran mayoría de los TBI no establecen ninguna disposición en torno a exigir o excluir explícitamente el ARI (Dietrich Brauch, 2017, pág. 7). 
En este marco, el laudo Maffezini c/. Reino de España ${ }^{6}$, resultante de la solicitud de arbitraje efectuada por el argentino Emiliano Agustín Maffezini contra el Reino de España a partir de la afectación que sufrió el demandante con respecto a su inversión en una empresa de productos químicos española, aduciendo el derecho aplicable que ampara dicha inversión, las disposiciones contenidas en el Tratado Bilateral de Inversión (TBI) suscripto oportunamente entre Argentina y España, el tribunal arbitral consideró que el Articulo X del mencionado TBI, establecía la posibilidad de someter a arbitraje una cuestión tratada en tribunales locales, pero no exigía el agotamiento de dicha vía. En este sentido, la cláusula del TBI buscaba establecer que las partes podían apelar a la jurisdicción local para resolver la controversia, sin perjuicio del acceso al arbitraje cumplido el plazo establecido en la cláusula, con independencia de la existencia de una resolución o no al respecto. En el marco de la pretensión del demandante, el tribunal resuelve que no correspondería su admisión, al menos, en función del ARI, ya que el demandante debía buscar dentro de los 18 meses previstos en la cláusula del TBI el acceso a la jurisdicción española. Al respecto, se puede afirmar entonces que el estatus del ARI se corresponde con lo convenido por las partes en el TBI, y no en tanto principio de derecho internacional en este caso. Por ende, podemos afirmar que se trata de una lectura flexible del principio, dado que, en caso de no establecerse en el TBI, no corresponde dicha exigencia en el marco de esta jurisdicción.

Sin embargo, la mayoría de los TBIs dejan al inversor elegir entre someter la disputa a los tribunales del Estado receptor de la inversión y/o el arbitraje ad hoc o institucional con preferencia al arbitraje CIADI. La tendencia actual es que dicho agotamiento no es obligatorio y sólo debe el inversor elegir

6 CIADI, Emiliano Agustín Maffezini (Demandante) c. Reino de España (Demandado). Caso CIADI N ${ }^{\circ}$ ARB/97/7. Decisión del tribunal sobre excepciones a la jurisdicción. Laudo del 25 de enero de 2000. 
una de las dos vías, y una vez realizada dicha elección se considera como definitiva cerrándose la otra vía.

En el mismo sentido, en el laudo Abaclat y otros c Argentina $^{7}$ se dirime la responsabilidad de Argentina en virtud de lo establecido en el TBI celebrado entre Argentina e Italia frente a una serie de acreedores, titulares de deuda pública argentina sometida a un proceso de restructuración tras la grave crisis financiera experimentada por el Estado. El laudo sobre jurisdicción y admisibilidad aceptó la competencia del tribunal para resolver el caso tanto, considerando el reclamo realizado por los boldouts demandantes como convencionales (en el marco del TBI) y no contractuales. En este marco, el planteo de Argentina fue que los acreedores no habían respetado el Art. 8 del TBI, que establecía un plazo de 18 meses de litigio, impidiendo al Estado receptor tratar la cuestión en jurisdicción local. Asimismo, plantea que los demandantes tenían la posibilidad de reclamar en Argentina y no lo hicieron. El tribunal arbitral concluyó al respecto que ello no impedía someter la cuestión a arbitraje y que la vía local no era obligatoria, además de no ser la más pertinente para resolver la diferencia en cuestión.

En este sentido, entonces, en los laudos analizados se visibiliza que el acceso al arbitraje en virtud del Convenio CIADI prevalece al principio que exige el ARI, por lo que su alcance es limitado.

\section{IV.3. MERCOSUR: Tribunales Arbitrales Ad-Hoc/Tribunal Permanente De Revisión (TPR)}

La no aceptación de Argentina a entablar Negociaciones Directas con Brasil no impide considerar que se ha cumplido dicha etapa prevista en el Protocolo de Brasilia como el primer escalón en el sistema de solución de controversias. Los estados deben procurar una solución mediante negociaciones directas

7 CIADI, Abaclat y Otros (Demandante) c. República Argentina (Demandada) Caso CIADI N. ${ }^{\circ}$ ARB/07/05, laudo del 4 de agosto de 2011. 
-a lo que se dio cumplimiento en el caso- y no de lograr que tales negociaciones se realicen y menos aún que sean eficaces. De lo contrario, además, caería todo el sistema de solución de controversias ya que su puesta en funcionamiento dependería de la voluntad de cada parte reclamada de entrar en negociaciones directas o no.

Este lineamiento en torno al requerimiento de negociaciones directas para el acceso a la jurisdicción está plasmado en el laudo "Pollos Enteros de Brasil", donde se plantea que la no realización de negociaciones directas por parte de Argentina no puede obstaculizar el desarrollo del procedimiento. En este sentido, se le reconoce a la parte reclamante la facultad de avanzar de etapa en etapa sin que la parte reclamada en ningún momento pueda detener la marcha del procedimiento, ya que una solución distinta no sería compatible con los fines institucionales del sistema de solución de controversias, quitándole sentido si el acceso a la jurisdicción es facultativo para la parte demandada. En el caso del laudo en cuestión, Argentina argumentó la existencia de procedimientos vinculados a las medidas antidumping en jurisdicción local como justificación para no presentar el caso ante el tribunal arbitral. Al respecto, el tribunal, ante la negativa de iniciar negociaciones diplomáticas, dio por cumplida la etapa de negociaciones previa a la admisión de la controversia siguiendo el referido lineamiento. Otro antecedente a destacar, en el ámbito del MERCOSUR, esta vez del Tribunal Permanente de Revisión (TPR), es el Laudo $\mathrm{N}^{\circ} 01 / 2012^{9}$, correspondiente a la presentación de Paraguay requiriendo medidas excepcionales de urgencia en virtud de

8 Tribunal Arbitral Ad Hoc Mercosur. Aplicación de Medidas Antidumping contra la exportación de pollos enteros provenientes de Brasil - Resolución N 574/2000 del Ministerio de Economía de la República Argentina (Brasil c. Argentina). 21 de mayo de 2001.

9 Tribunal Permanente de Revisión Mercosur. Laudo No. 01/2012. Procedimiento Excepcional de Urgencia solicitado por la República del Paraguay en relación con la suspensión de su participación en los Órganos del MERCOSUR y la incorporación de Venezuela como Miembro Pleno", del 21 de julio de 2012. 
lo establecido en el Art. 24 del Protocolo de Olivos (PO), en atención a la suspensión del Estado impulsada en la Cumbre de Presidentes realizada ese mismo año. En este caso, los miembros demandados por Paraguay (Argentina, Brasil y Uruguay), alegaron que no se había cumplido con el Art. 23 del PO para acceder directamente al TPR, no habiendo intentado negociaciones directas -al no acreditarse comunicaciones conforme el Art. 5.1 del PO-. En este sentido, no habiendo consentimiento de los estados miembro a la jurisdicción ni iniciativa de negociaciones directas por parte de Paraguay, el TPR rechazó el reclamo. Más allá de la inexistencia del requerimiento de ARI, del análisis de los dos laudos en cuestión se infiere una interpretación rígida del requerimiento de negociaciones directas previas al sometimiento de la cuestión en la jurisdicción, en tanto, si bien los actos requeridos no son muy exigentes -la comunicación del referido Art. 5.1- se puede advertir una lectura inflexible en cuanto al cumplimiento de dicha disposición.

\section{IV.4. Órgano de Solución de Diferencias - Organización Mundial de Comercio (OSD-OMC)}

La situación del sistema de integración económica del OSD-OMC es similar a lo que sucede con el CIADI. Al respecto, no existen disposiciones respecto del ARI en el GATT (Acuerdo General sobre Aranceles Aduaneros y Comercio, 1947). Asimismo, en los Acuerdos Antidumping, como en los TBI, no se tienden a incorporar requisitos en dicho sentido (Lichtenbaum, 1998, pp. 1220-1222). En este sentido, lo que el Entendimiento sobre Solución de Diferencias (ESD) de la OMC establece es la exigencia de llevar adelante una instancia previa de consultas para así tender a soluciones negociadas (Art. 4). De no prosperar las mismas luego de 60 días de solicitadas las consultas, el Estado reclamante puede solicitar ya la constitución de un grupo especial (establecidos en cada controversia a tal efecto). En definitiva, la regla del ARI no se extiende a esta entidad. 
En torno a la consideración de condiciones de admisibilidad vinculables con la regla de ARI, se pueden mencionar antecedentes como DS60 (1998) entre México y Guatemala ${ }^{10}$ por investigación antidumping llevada adelante por Guatemala respecto de la importación de cemento Pórtland desde México. En este caso, en el marco de las cuestiones preliminares, Guatemala sostuvo que las medidas antidumping tomadas habían sido provisionales o "compromisos de precios", pero no definitivas, mientras que México sostuvo que había habido medidas definitivas no expuestas en el periodo de consultas -es decir, no notificadas- como es el caso del inicio de la investigación por vía interna, incumpliendo lo dispuesto en el Acuerdo Antidumping respectivo. En este sentido, el Grupo Especial consideró que Guatemala, al no haber efectuado una notificación a México antes de la fecha de publicación del aviso de iniciación, incumplió con lo establecido en el párrafo 5 del artículo 5 del Acuerdo Antidumping (Párr. 7.39), recomendando entonces la revocación de la medida antidumping adoptada con respecto a las importaciones de cemento mexicano en tanto se consideró que la no notificación puso a México en una posición desventajosa (Recomendación 8.6). En esta resolución podemos observar que el requerimiento de notificación de procedimientos internos por parte de los estados son condición para el sometimiento de la diferencia en el OSD-OMC, en un sentido, asimilable al requerimiento de ARI.

Un caso posterior, DS241 (2003) entre Argentina y Brasil ${ }^{11}$ con respecto a las medidas antidumping impuestas por Argentina sobre las importaciones de pollos de Brasil. En dicho caso, el grupo especial condenó las medidas argentinas debido a su

\footnotetext{
10 Órgano de Solución de Diferencias (OMC), "Guatemala - Investigación antidumping sobre el cemento Pórtland procedente de México, DS60. Informe del Grupo Especial del 19 de junio de 1998.

11 Órgano de Solución de Diferencias (OMC), "Argentina - Derechos antidumping definitivos sobre los pollos procedentes del Brasil", DS241. Informe del Grupo Especial del 22 de abril de 2003.
} 
incompatibilidad con el Acuerdo Antidumping en cuestión y recomendó a Argentina adoptar medidas al respecto conforme la normativa de la OMC. En este caso, Argentina alegó la existencia de procedimientos previos en jurisdicción local y ante el MERCOSUR, por lo que el OSD-OMC debía abstenerse de pronunciarse. Subsidiariamente, habían solicitado la aplicación de la resolución del Tribunal del Mercosur al respecto, en tanto Brasil había sometido la cuestión en ámbitos diversos simultáneamente, invocando el instituto del estoppel (o doctrina de actos propios (Párr. 7.17). En ese sentido, el Grupo Especial sostuvo que dichos planteos no resultaban admisibles. En este caso, la alusión indirecta a la regla de ARI es más notoria, aunque se apela a la doctrina de los actos propios. En este sentido, los argumentos no fueron admitidos por el Grupo Especial.

Al respecto, el análisis de los referidos casos, teniendo en consideración el propio diseño institucional del OSD-OMC, nos permite aseverar que, en la medida que se cumpla con la instancia preliminar de consultas y se notifiquen las investigaciones internas, el criterio de admisibilidad de las diferencias es amplio y no restrictivo, en tanto el criterio adoptado en los casos no considera la regla de ARI. En tal sentido, la primacía de la jurisdicción es significativa.

\section{IV.5. Corte Interamericana de Derechos Humanos (Corte IDH)}

En el caso de la Corte IDH, el instituto tiene un desarrollo significativo a nivel jurisprudencial. La falta de ARI ha constituido históricamente la excepción preliminar por excelencia interpuesta por los estados demandados ante la Comisión Interamericana de Derechos Humanos o la Corte IDH (Rey, 2006, pp. 1-3). El Art. 46 de la Convención Americana de Derechos Humanos (CADH) exige el agotamiento de recursos de jurisdicción interna como requisito de admisibilidad. No obstante, el inciso 2 del mismo artículo establece como excepciones los supuestos en los que no se consagre el debido proceso legal en el derecho local; no se haya permitido al presunto lesionado 
en sus derechos el acceso o agotamiento de recursos o bien haya retardo injustificado en la resolución de los casos en jurisdicción local. Asimismo, la Opinión Consultiva OC-11/90 menciona como excepción los casos en los que los recursos no están disponibles, sea por una razón legal o de hecho ${ }^{12}$. El análisis de la jurisprudencia de la Corte IDH permite observar que la interpretación de los requerimientos del Art. 46 es más bien flexible, en tanto la ponderación de las excepciones, tanto en la normativa como en la posterior interpretación judicial da cuenta de la consideración integral de los factores que condicionan el efectivo cumplimiento de dicho requerimiento procesal. En el caso Velázquez Rodríguez ${ }^{13}$, concerniente al secuestro y desaparición de un estudiante universitario en el marco de una práctica sistemática llevada a cabo por el Estado de Honduras por parte de las FF:AA o Fuerzas Paramilitares bajo su conducción, la Corte IDH, en el marco de las excepciones preliminares, plantea que no es procedente la excepción interpuesta por el Estado hondureño, en tanto, lejos de contar con una administración de justicia funcional al rol complementario de la Corte (Párr. 61) conforme el preámbulo de la $\mathrm{CADH}$, ejerció la práctica de manera sistemática. En este sentido, si bien los recursos internos no habían sido agotados por el demandante, "la fundamentación de la protección internacional de los derechos bumanos radica en la necesidad de salvaguardar a la víctima del ejercicio arbitrario del poder público" (Párr. 93). Asimismo, la Corte IDH sostuvo que en tanto los estados partes se obligan a suministrar recursos judiciales efectivos a las víctimas de violación de Derechos Humanos y que los recursos deben sustanciarse conforme las reglas del debido proceso, cuestión que no se daba en el caso en trato, por lo que el agraviado no

\footnotetext{
12 Excepciones al agotamiento de los recursos internos (arts. 46.1, 46.2.a y 46.2.b Convención Americana sobre Derechos Humanos), Corte IDH, Opinión Consultiva OC-11/90, 10/08/1990, parágs. 20-22.

13 Corte Interamericana de Derechos Humanos, Caso Velásquez Rodríguez, Excepciones preliminares, sentencia del 26 de junio de 1987.
} 
estaba obligado a interponer los recursos internos y, lo que es más, su planteo en torno a la ineficacia de los recursos y el incumplimiento del debido proceso implicaba imputar al Estado como agente involucrado en una nueva violación a las obligaciones de la CADH (Párr. 91), siendo estos incumplimientos elementos probatorios "de una práctica gubernamental orientada hacia la desaparición forzada de personas" (Párr. 83). En este sentido, y considerando todas estas cuestiones, la Corte IDH desestima la excepción preliminar planteada por Honduras. En este antecedente jurisprudencial, se pone de manifiesto la ponderación de las excepciones y sus supuestos en juego a fin de exceptuar al demandante del requerimiento de ARI.

Otro antecedente jurisprudencial representativo del alcance de la regla es el caso Castillo Patruzzi y otros ${ }^{14}$. El caso se enmarcó en un conflicto entre las FFAA y grupos armados en Perú, en el cual detuvieron a Jaime Castillo Patruzzi y otros militantes, tras lo cual las propias FFAA llevaron adelante un proceso militar bajo el cargo de traición a la patria, no contando los detenidos con defensa legal alguna y habiéndose rechazado múltiples hábeas corpus. Al respecto, Perú argumentó que la CIDH había admitido el caso cuando estaba pendiente un proceso en jurisdicción local contra las supuestas víctimas (Párr. 52). No obstante, la Corte consideró que el caso había sido recibido pero no admitido ni tramitado cuando el proceso local se encontraba todavía en última instancia (Párr. 54), y lo admitió una vez que existía una sentencia definitiva de la justicia militar peruana (Párr. 55). En este sentido, la Corte consideró que no se había dado cuenta del cumplimiento del debido proceso legal (Párr. 53) y que el Estado peruano no alegó en la instancia procesal prevista la falta de ARI, incurriendo entonces en la admisión tácita de la inexistencia de dichos recursos o del agotamiento efectivo (Párr. 56).

14 Corte Interamericana de Derechos Humanos. Caso Castillo Petruzzi y otros. Excepciones preliminares, sentencia de 4 de septiembre de 1998. 
Asimismo, el Estado peruano no había dado cuenta de la efectividad de los recursos internos, siendo que no había otorgado los hábeas corpus (Párr. 63). A su vez, se había negado a la delegación chilena la visita a los detenidos, violando lo dispuesto al respecto en la Convención de Viena sobre Relaciones Consulares, excepción admitida en tanto la obligación aludida no estaba comprendida en la CADH (Párr. 68). En definitiva, los peticionarios estaban eximidos de agotar los recursos internos, en virtud de lo establecido en el Art. 46.2 de la CADH.

Los dos antecedentes jurisprudenciales analizados permiten aseverar que, en el Sistema Interamericano, tanto a nivel normativo como jurisprudencial, la flexibilidad del requerimiento de agotamiento de recursos internos es amplia, dada la gama de excepciones admitidas y consideraciones ponderadas.

\section{IV.6. Tribunal Europeo de Derechos Humanos (TEDH)}

En el caso del Sistema Europeo de Protección de Derechos Humanos se incluyen mecanismos de garantía, orientados a interpretar y controlar los derechos contenidos en el Convención Europea de Derechos Humanos (CEDH). El Art. 35 de la CEDH establece que no se podrá recurrir al TEDH sino una vez agotados los recursos internos, y en el plazo de seis meses a partir de la decisión definitiva local. Al respecto, el examen de dos antecedentes jurisprudenciales recientes nos permite hacer una reconstrucción de su lectura de la regla del ARI.

El caso Del Pino García y Ortín Méndez contra España ${ }^{15}$, concerniente al reclamo dos personas afectadas por ruidos y vibraciones provenientes de la maquinaria correspondiente a una compañía de seguros que se encontraba contigua a su domicilio, el cual fue efectuado y recurrido en las distintas instancias locales hasta llegar al Tribunal Constitucional español

15 Tribunal Europeo de Derechos Humanos. Caso “Don Antonio DEL PINO GARCIA y María ORTÍN MÉNDEZ contra España sobre admisibilidad", demanda N²3651/07. Sentencia del 14 de junio de 2011. 
mediante un amparo, el cual fue rechazado por haber incumplido el plazo de presentación requerido. En este marco, los demandantes realizaron una presentación al TEDH, argumentando la violación de sus derechos a la integridad física, moral e inviolabilidad del domicilio. Al respecto, España opuso la excepción de falta de ARI (Art. $35 \mathrm{CEDH}$ ), en tanto el recurso de amparo formalizado por los demandantes ante el Tribunal Constitucional fue declarado inadmisible por extemporáneo. En este sentido, el TEDH reafirmó el requisito del ARI, sosteniendo que no hay agotamiento cuando un recurso ha sido declarado inadmisible por falta de cumplimiento de un requisito formal (Párr. 28) con la salvedad de casos de arbitrariedad (Párr. 30). Asimismo, el TEDH sostuvo que no es competente para analizar las condiciones de admisibilidad planteadas por los estados locales (Párr. 31). A su vez, afirmaron que el incumplimiento del plazo para presentar el amparo constituía una falta objetiva y la notificación de inadmisibilidad y concesión de plazo adicional era procedente solo en caso de darse vicios reparables, denegando por lo tanto la presentación de los demandantes por incumplimiento del Art. 35 del CEDH.

Por su parte, en el caso Zoubida Barik Edidi contra Españ $a^{16}$, concerniente a un reclamo efectuado por una abogada que había sido discriminada por el uso de atuendos propios de la religión islámica en el marco de un proceso. En este marco, hizo un reclamo al observatorio del Colegio de Abogados que fue rechazado. Reiteró el reclamo en múltiples instancias, incluyendo un recurso ante un tribunal incompetente en la materia. Frente al silencio administrativo, la demandante recurrió al Tribunal Constitucional español, que desestimó el reclamo dado que no se podía reprochar a un tribunal incompetente su falta de accionar. La demandante interpuso un recurso de nulidad, que también fue desestimado. Seguidamente, interpuso un amparo

16 Tribunal Europeo de Derechos Humanos. Caso "ZOUBIDA BARIK EDIDI contra España", demanda N ${ }^{0} 6177 / 2010$. Sentencia del 26 de abril de 2016. 
en virtud de la afectación de sus derechos a la igualdad ante la ley, libertad religiosa, intimidad y derecho a la tutela judicial. El mismo fue también rechazado y en función de ello acudió al TEDH. Al respecto, el Estado español alegó la inadmisibilidad del caso por falta de ARI, dado que la demandante no había impugnado una de las decisiones que rechazaban un recurso por extemporaneidad. Asimismo, se plantea que el rechazo del recurso de daba por incumplimientos procesales. Al respecto, el TEDH plantea que la presentación extemporánea del primer recurso de alzada por parte de la demandante ha privado a los tribunales internos de la posibilidad de pronunciarse sobre el fondo de sus pretensiones (Párr. 48), no cumpliéndose el ARI. Por lo tanto, el TEDH desestima el planteo.

En ambos antecedentes jurisprudenciales podemos ver que, en el marco de los tribunales Regionales con Competencia en materia de Derechos Humanos (y en contraposición con el caso de la Corte IDH), la regla del ARI en el TEDH es rígida en su alcance.

\section{IV.7. Corte Penal Internacional (CPI)}

Las condiciones de admisibilidad de los casos por parte de la CPI están regidas por lo establecido en el Art. 17.1 del Estatuto de Roma de la Corte, estableciéndose que las cuestiones serán inadmisibles cuando: el asunto sea objeto de un proceso en un Estado con jurisdicción, siempre que esté dispuesto y pueda llevarla a cabo; cuando el Estado haya decidido no llevar a cabo la persecución penal; la persona del caso ya haya sido enjuiciada y cuando el asunto no sea de gravedad suficiente para justificar la intervención de la CPI. Simultáneamente, el Art. 17.2 profundiza los términos en tanto establece criterios de examen del supuesto de tramitación por jurisdicción interna, en tanto éste debe darse de acuerdo a los principios del debido proceso y garantías reconocidos en el derecho internacional. En este sentido, en el marco de la regla cuyo abordaje motiva el presente trabajo, se plantea una lectura de la interacción 
entre la jurisdicción internacional y la jurisdicción local en la CPI como dimensión de análisis asimilable a la regla del ARI, a fin de determinar el alcance del requerimiento de abordaje preliminar de la cuestión.

Entre los antecedentes jurisprudenciales del tribunal, el caso "Katanga y Chui" ${ }^{17}$ correspondiente a la resolución acerca de una apelación del acusado presentada ante la CPI. El caso en cuestión corresponde a la acusación sobre el ex - líder militar Katanga, al que se lo acusa de haber sido cómplice del asalto a una aldea en la República Democrática de Congo, donde murieron doscientas personas. Los cargos atribuidos fueron por crímenes de guerra y de lesa humanidad.

En este caso, frente a la impugnación impulsada por la defensa de Katanga, se plantea que el Estado congoleño se estaba llevando a cabo una investigación por los mismos hechos motivaban la causa en análisis, violando el Principio de Complementariedad, según el cual la CPI interviene cuando los estados no pueden o no están dispuestos a hacerlo (Art. 17). Esta cuestión es descartada por el tribunal, en tanto los informes emitidos por el Estado era de índole procedimental. En este sentido, se juzgó que el caso presentado ante la CPI no era el mismo que el indagado por jurisdicción interno, por lo que la cuestión resultaba admisible (Selis, 2016, pág. 41).

En el marco de la lectura de la complementariedad en el caso, la CPI consideró que el supuesto desinterés del Estado congoleño en investigar la cuestión se corresponde a la cesión de la jurisdicción a la CPI. En este sentido, se considera que el principio de complementariedad faculta a los estados a ceder su jurisdicción. Frente a la prelación de la jurisdicción interna frente a la jurisdicción internacional, en este caso se parte de la voluntad manifestada por el Estado, en el marco del equilibrio

17 Corte Penal Internacional. The Prosecutor v. Germain KATANGA and Mathieu NGUDJOLO CHUI - [Decisión sobre la apelación del Sr. Katanga contra la Decisión oral de la Cámara de Primera Instancia II, del 12 junio de 2009, sobre la Admisibilidad del Caso"], Sentencia del 25 de septiembre de 2009 
entre la primacía del orden interno y la finalidad misma de la CPI, que consiste en perseguir los casos en pos de evitar la impunidad, conforme lo establece su Estatuto. Si los estados no quieren o no pueden llevar adelante el proceso, entonces la CPI está habilitada a intervenir (Selis, 2016, pp. 39-40). En síntesis, la no persecución penal en jurisdicción interna no contraria el principio de complementariedad en este caso.

Del caso analizado, podemos aseverar que el margen de intervención de la CPI es amplio, dada la rigurosidad bajo la cual se examinan los alcances de los procesos llevados a cabo en jurisdicción interna en el marco de las impugnaciones que se presentan para someter las cuestiones a jurisdicción internacional, en tanto pondera no solo la realización o no de los procesos, sino también la efectividad de los mismos.

Por su parte, en el antecedente "Ruto, Kosgey y Sang"18, la CPI intervino al procesar a William Ruto por su participación en los crímenes de lesa humanidad cometidos durante los hechos de violencia postelectoral de 2007-2008 en Kenia. Frente a la impugnación a la admisibilidad del caso por parte de la CPI llevada adelante por el Estado keniata, con arreglo al apartado b) del párrafo 2 del artículo 19 del Estatuto de Roma. Al respecto, la Corte consideró que Kenia no había presentado información que demostrara que se habían tomado medidas concretas de investigación contra los sospechosos (Párr. 82) en tanto al momento de presentar la impugnación se le había requerido al Estado que se demostrara que se habían tomado medidas concretas y progresivas para llevar a cabo la investigación, lo cual no sucedió (Párr. 83). También se refirió a la negativa de Estado a asistir a la audiencia oral previa a la evaluación de la impugnación de admisibilidad (Párr. 102) y a la discrecionalidad del tribunal preliminar para sustanciar el proceso de impugnación

18 Corte Penal Internacional. Fiscal c. William Samoei Ruto, Henry Kiprono Kosgey and Joshua Arap Sang" (Caso ICC-01/09-01/11-101) Decisión sobre la solicitud del Gobierno de Kenia de inadmisibilidad del caso conforme al artículo 19 (2)(b) del Estatuto, Sentencia del 30 de mayo de 2011. 
(Párr. 110). En este sentido, la CPI ratificó en esta instancia lo resuelto en la instancia preliminar, en tanto consideró que el Estado no acreditó la consecución de una investigación interna. Con respecto a dicha resolución, cabe mencionar que es visible la rigidez del tribunal en torno a la acreditación de los procesos internos $\mathrm{y}$, en tal sentido, el criterio de admisibilidad resulta flexible, en tanto la impugnación de la misma debe responder a estándares rigurosos.

Analizados en conjunto, los antecedentes jurisprudenciales abordados permiten aseverar que, en el caso de la CPI, las condiciones de admisibilidad en general -categoría que nos permite poner en diálogo su dinámica institucional con la categoría de ARI- resulta flexible, y constituye un caso que contribuye al diagnóstico preliminar de las jurisdicciones internacionales.

\section{III.8. Tribunal Internacional del Derecho del Mar (TIDM)}

Con relación a la regla de ARI, la Convención de las Naciones Unidas sobre el Derecho del Mar (CONVEMAR) establece en su art. 295 que "las controversias que surjan entre Estados Partes con respecto a la interpretación o la aplicación de esta Convención podrán someterse a los procedimientos establecidos en esta sección sólo después de que se hayan agotado los recursos internos, de conformidad con el derecho internacional". No obstante, en del desarrollo jurisprudencial del TIDM se han dado casos donde se estableció un corrimiento de los lineamientos generales a nivel normativo. En primer lugar, se puede hacer un análisis del caso Camouco $^{19}$, en el cual Panamá presentó una demanda contra Francia sobre la pronta liberación de un buque - que enarbolaba pabellón panameño- y de su capitán, apresados por una fragata francesa, resolviendo el TIDM la liberación del buque y su capitán previo depósito de una fianza. En dicho caso, Francia había objetado la admisibilidad planteando

\footnotetext{
19 Tribunal Internacional del Derecho del Mar. Caso "Camouco" (Panamá v. Francia), pronta liberación, sentencia del 7 de febrero del 2000.
} 
el incumplimiento de la regla de ARI establecida en el Art. 295 de la CONVEMAR. Al respecto, el TIDM sostuvo que la regla del ARI no constituía un requisito necesario en el supuesto del Art. 292 (Párr. 55). Asimismo, planteó que no era lógico leer la regla de ARI en el supuesto del 292, ya que dicho supuesto normativo había sido diseñado para la liberación de buques y tripulaciones en el marco de una detención prolongada resultante de la imposición de cargos irrazonables, preservando a su vez los intereses del Estado ribereño al imponer una fianza razonable, sin perjuicio de eventuales procedimientos internos ulteriores (Párr. 57). A su vez, planteó que el régimen del Art. 292 constituía un remedio independiente y no contrario a una decisión local (Párr. 58) y no representa una limitación en torno a su propia finalidad. Asimismo, el tiempo de agotamiento de recursos internos es mucho más extenso que el remedio provisto por la medida concerniente a la pronta liberación (Párr. 58).

Por su parte, el caso $\mathrm{N}^{\circ} 2$ relativo al Saiga ${ }^{20}$, concerniente a la solicitud de medidas provisionales efectuada por parte del Gobierno de San Vicente y las Granadinas (en adelante "SVyLG") mientras se constituía un tribunal arbitral de conformidad con el Anexo VII de la CONVEMAR. En este caso, el TIDM, en tanto el Estado de Guinea había liberado el buque del demandante y su capitán, estableció una medida provisional según la cual Guinea debía abstenerse de adoptar cualquier tipo de medida contra Saiga y su tripulación. Asimismo, el Tribunal recomendó a ambas partes no emprender ninguna acción que pudiera agravar la controversia. Posteriormente, los gobiernos de ambos estados acordaron someter el fondo de la controversia relativa al Saiga al Tribunal. En su sentencia, el TIDM resolvió que Guinea había violado los derechos de SVyLG conforme CONVEMAR al haber capturado al buque y detenido a su tripulación, decidiendo que Guinea debía pagar una indemnización a SVyLG.

\footnotetext{
20 Tribunal Internacional del Derecho del Mar. Caso M/V "SAIGA" (No. 2) (San Vicente y las Granadinas v. Guinea), medidas provisionales, orden del 11 de marzo de 1998 y sentencia sobre el fondo de la controversia del 1 de julio de 1999.
} 
En esta controversia, entre las objeciones planteadas por Guinea, se planteó que una serie de reclamos llevados a cabo por personas afectadas por las medidas del Estado contra el buque eran inadmisibles en tanto las personas interesadas no habían agotado los recursos internos en los términos del Art. 295 de la CONVEMAR. Al respecto, el TIDM sostuvo que los derechos afectados en dichos casos pertenecían a SVyLG en virtud de lo establecido en los Arts. 33, 56, 58, 111 y 292 de la CONVEMAR (Párr. 97), considerando entonces que la regla de ARI con relación a dicha afectación no era aplicable al caso (Párr. 98).

En ambos casos, si bien se consagra normativamente la regla del ARI, el desarrollo jurisprudencial permite observar, en términos de admisibilidad, un criterio amplio que consolida el estatus de la jurisdicción (también es fundamental en tal sentido los supuestos de jurisdicción obligatoria establecidos en la CONVEMAR) y permite reconstruir la regla del ARI con márgenes de flexibilidad.

\section{IV.9. Tribunales Penales Internacionales Ad-Hoc: el Tribunal Penal Internacional para la Ex Yugoslavia (TPIY) y el Tribunal Penal Internacional para Ruanda (TPIR)}

Entre los tribunales con competencia para entender en asuntos contra individuos, los casos del TPIY y el TPIR cuentan con características significativas para el análisis que motiva el presente trabajo. El Art. 9 del Estatuto del Tribunal establece la jurisdicción concurrente para enjuiciar personas que hayan violado el Derecho Internacional Humanitario en el territorio de la Ex - Yugoslavia, estableciendo a su vez la primacía del TPIY sobre los tribunales nacionales. Por su parte, el Art. 10, establece que los casos juzgados por el TPIY no serán juzgados en tribunales nacionales, a la vez que los casos juzgados en tribunales nacionales pueden ser juzgados en el TPIY. Desde la clave del ARI, es posible leer la competencia concurrente, en tanto pone en juego el orden de prelación entre la jurisdicción 
internacional y la jurisdicción local. Al respecto, el fallo Dusko Tadic $^{21}$, correspondiente al juzgamiento del ex - funcionario por crímenes de lesa humanidad, donde la defensa de Tadic invocó una excepción a la primacía del TPIY en tanto afectaba la soberanía de Bosnia y Herzegovina. Con relación al principio de jurisdicción concurrente, alegó que Tadic tenía un proceso en curso en Alemania. Al respecto, el TPIY sostuvo la primacía del tribunal (Art. 9 ETPIY). En cuanto al planteo de la soberanía de los estados, remite al Art. 10, ratificando el sentido de dotar de primacía a los tribunales creados a tal efecto, en pos de luchar contra la impunidad contra estos crímenes. En este sentido, la resolución ratifica la primacía de la jurisdicción internacional y, en tal sentido, no exige el abordaje desde la jurisdicción local (análogamente, se puede afirmar al respecto que no existe ninguna regla que exija el tratamiento preliminar en jurisdicción local, como lo supone, en general, la regla de ARI).

En el caso del TPIR, el reglamento es similar en cuanto a la jurisdicción concurrente (Art. 8 Estatuto) y la primacía de la jurisdicción internacional sobre la local. (Arts. 8 y 9), con la salvedad de una facultad del TPIR conferida por el Art. 8.2, que prevé a posibilidad de solicitar la inhibición de jurisdicción.

El caso del TPIR Fiscal vs. Bernard Munyagishari ${ }^{22}$. Concerniente al juzgamiento del comandante involucrado en el Genocidio de Ruanda (1994) de la población de la etnia Tutsi. En dicho caso, la defensa del genocida sostenía que el acusado -detenido en Congo- era nacional de dicho Estado, por lo que debía ser juzgado ahí. Al respecto, el TPIR sostuvo que, incluso siendo nacional de dicho país, Congo estaba obligado a extraditarlo a Ruanda de acuerdo con los arts. 8 (primacía del TPIR)

\footnotetext{
21 "The Prosecutor v. Dusko Tadic - Decision on the defence motion for interlocutory appeal on jurisdiction" [Decisión sobre la moción de apelación interlocutoria sobre jurisdicción presentada por la Defensa], Sentencia del 2 de octubre de 1995.

22 Tribunal Penal Internacional para Ruanda. The Prosecutor v. Bernard Munyagishari", Caso No. ICTR-2005-89-R11bis, (Fiscal vs. Bernard Munyagishari), Decisión sobre la solicitud del Fiscal de referir el caso a la República de Ruanda, Sentencia del 6 de junio de 2012.
} 
y 28 (obligación de cooperar) de su Estatuto, en tanto existe primacía para enjuiciar personas por graves violaciones al derecho internacional humanitario (Párr. 25). Asimismo, la defensa alegó que el acusado debía ser juzgado en Congo dado que era el lugar más apropiado. Al respecto, el TPIR juzgó innecesario evaluar el argumento dada la primacía del tribunal (Párr. 31).

En ambos antecedentes jurisprudenciales se puede advertir que se consagra la primacía del CESL sobre los tribunales locales.

\section{IV.10. Tribunales Penales Internacionalizados (TPI's): Sierra Leona, Camboya y Timor Oriental ${ }^{23}$}

El caso de los TPI's es asimilable al de los tribunales $A d-H o c$ en cuanto a su complejidad y especificidad. En el caso de la Corte Especial de Sierra Leona (CESL) la jurisdicción es concurrente (Art. 8 de su Estatuto), consagrándose la primacía del CESL sobre los tribunales nacionales, a la vez que se establece la facultad del tribunal de solicitar que defiera su competencia. Asimismo, el Art. 9 establece que los tribunales nacionales no pueden juzgar casos tratados en la CESL, mientras que existen supuestos en los que puede ser juzgado en la CESL habiendo sido juzgado previamente en tribunales nacionales. En cuanto a su alcance en términos de competencia territorial, alcanza a violaciones al derecho internacional humanitario cometidas desde 1996 en Sierra Leona.

En el caso de las Cámaras Extraordinarias en la Corte de Camboya (CECC), las Salas tienen competencia exclusiva para juzgar los crímenes cometidos en su jurisdicción. Fueron establecidas para perseguir a los dirigentes del Jemer Rojo así como aquellos vinculados con los crímenes cometidos durante el régimen de la Kampuchea Democrática (Arts.1, 5.3, y 6.3 del

\footnotetext{
23 Se examinará la regulación general de las tres jurisdicciones. Siendo que en ninguna de las tres se consagra la regla de agotamiento de recursos internos, se reparará en las cuestiones particulares equiparables a los Tribunales Penales Ad-Hoc, tomando los antecedentes de estos últimos como casos testigo.
} 
Acuerdo ONU-Camboya). Esta jurisdicción tiene su estatus en virtud del acuerdo suscripto por el Estado y la ONU, pero se tratan de tribunales integrados a la estructura judicial local. El alcance territorial del tribunal no está especificado en su reglamento interno ni en el acuerdo, pero su alcance en nacional dada la estructura del tribunal. La competencia en el caso de las Salas es exclusiva, dada su estructura de origen nacional (Fraschina, 2008, pp. 76-79).

Por su parte, las Salas para crímenes serios de Timor Oriental (SETO), la competencia del tribunal es exclusiva (dado el estatus conferido por la ONU, a la vez de su estatus local $)^{24}$ y la competencia está circunscripta a los delitos cometidos en Timor Oriental antes del 25 de octubre de $1999^{25}$. Asimismo, las SETO tienen jurisdicción universal (Fraschina, 2008, pp. 125-126).

Del abordaje de los tres casos, podemos identificar que no existe ninguna dinámica entre jurisdicción local e internacional en los casos de la CECC y las SETO, mientras que en la CESL se consagra la primacía de la jurisdicción internacional por sobre los tribunales nacionales, por lo que no se puede interpretar de ninguno de los casos reglas análogas al ARI.

\section{Consideraciones finales}

El presente trabajo tuvo como objetivo reconstruir una categorización global del principio de agotamiento de recursos internos a nivel global y de las excepciones admitidas de forma unánime, en tanto condición de admisibilidad a la jurisdicción internacional. El análisis de las reglamentaciones y antecedentes jurisprudenciales de cada jurisdicción permite sostener la imposibilidad de establecer lineamientos de alcance global en

\footnotetext{
24 Administración de Naciones Unidas en Timor Oriental (Regulación Nro. 11/2000. Sección 10.1).

25 Administración de Naciones Unidas en Timor Oriental (Regulación Nro. 11/2000. Sección 5.2).
} 
materia de agotamiento de recursos internos. Al respecto se plantean tres tesis:

(I) El desarrollo institucional de las jurisdicciones internacionales es profundamente heterogéneo, por lo que la disimilitud entre los distintos diseños institucionales -sujetos a sus objetivos institucionales, coordenadas geopolíticas y coyunturas regionales o locales- da cuenta de un grado de fragmentación que impide identificar patrones globales en materia de ARI, ello debido a que si bien existen casos donde la regla de ARI se exige a nivel normativo, con distintos desarrollos jurisprudenciales (en la Corte IDH, un criterio más flexible en materia de excepciones; una lectura más rígida en el caso del TEDH), en muchos otros, la regla no está prevista por el carácter de la institución (por su estatus arbitral en los casos del CIADI y de los tribunales de MERCOSUR; por su estatus especial en los casos de los Tribunales Ad-Hoc y los TPI's).

(II)De la reconstrucción de las interpretaciones del principio en cada uno de los casos, se identifica como patrón general la flexibilidad de las jurisdicciones en términos de admisibilidad y la primacía de la jurisdicción internacional por sobre la jurisdicción local. En la mayoría de los casos, se realizaron aproximaciones a categorías análogas en tanto ponían en juego las dinámicas entre los dos niveles jurisdiccionales, como es el caso del principio de complementariedad en la CPI o la competencia concurrente con primacía del tribunal internacional en el TPIY, TPIR y CESL. Asimismo, en los casos donde no había referencia alguna en sus diseños institucionales (como en los supuestos en los que la posibilidad de exigir el ARI estaba sujeta a su inclusión en acuerdos bilaterales, como es el caso de los TBI's en el CIADI) se identificó una lectura flexible en tanto la tendencia versa sobre la admisibilidad de los casos con independencia de la situación en las jurisdicciones locales (como el caso de los tribunales del MERCOSUR). En este sentido, se identifica una tendencia general a la flexibilidad subsumible en las condiciones de admisibilidad y la primacía 
de la jurisdicción internacional, pero ello no es posible en términos de ARI.

(III) Del abordaje realizado en el presente trabajo se deduce que el escenario de fragmentación del Derecho Internacional no solo condiciona su sistematización, sino que la imposibilita. No obstante, es posible identificar tendencias globales, como la primacía de la jurisdicción internacional en la consideración de los tribunales y la flexibilidad en términos de condiciones de admisibilidad. 